\title{
A REPRESENTATIONAL FRAMEWORK FOR SUSTAINABLE DESIGN
}

\author{
ROBERT GROVER, STEPHEN EMMITT \& ALEXANDER COPPING \\ University of Bath, UK
}

\begin{abstract}
Sustainable design is a widely accepted concept, but there is no general consensus on its realisation, as evidenced by the range of strategies in the built environment that fall under the umbrella of "green" design. These vary from technological innovation to empowering social action; which often represents competing world-views, that are often seemingly contradictory or incompatible. Therefore, design for sustainability requires the designer to advocate an ethical or moral stance; and to decide on where to assign value. Despite this, there is no coherent framework which structures the complexity of this field. In this paper, existing models of sustainable development and design are analysed and a new framework that classifies alternative approaches is proposed. The framework presents conflicting paradigms on a continuum, which provides structure to the discourse on sustainable design, allowing building designers to map their own strategic approaches, recognise inconsistencies and reveal potential future directions. Rather than suggesting that sustainability has a single definable outcome; the framework provides a means to contextualise different, yet equally valid, design scenarios.
\end{abstract}

Keywords: design, green architecture, green design, planning, sustainable design, sustainable framework.

\section{INTRODUCTION}

Sustainable design represents a significant challenge to the future of architecture. While sustainability is a widely accepted concept, it is a "wicked problem" [1]: it is poorly defined, has any number of possible solutions, and has no "stopping rule" or means to determine success. The seemingly singular common goal defined by the Brundtland Report [2] is open to multiple conflicting interpretations. This variety is evident in the realm of architecture, where practice embodies numerous sustainable paradigms, often in direct competition [3]. This research draws from models of sustainable development and presents a framework that maps and categorises the competing approaches. Rather than searching for an objective categorisation of sustainable design [4], this research seeks a means to represent and embrace plurality. An evaluative framework is constructed; which, rather than attempting to describe a singular idea in a comprehensive manner, can be used to critique possible approaches.

\section{MAPPING SUSTAINABLE DESIGN}

A range of sustainable development models and frameworks have attempted to organise the complex conceptual arguments and accumulated knowledge of discourse [5]. They can be used to evaluate and guide sustainable development strategy and policy. While there is huge variation, these can be classified by the nature of the information they structure. Nominative models capture a particular concept, attempting to holistically describe either its characteristics or principles. A basic example is the three pillars of environmental, economic and social sustainability (which emerged from the Brundtland Report [2]) and attempt to describe the general conditions for meeting sustainable development. By contrast, evaluative models critique a concept in relation to set criteria [6]. For example, Hopwood et al. [7] analyse competing sustainable agendas through the dimensions of social equity and environmental concern, providing a description of the sustainable development landscape. 
2.1 Nominative models of sustainable development

Nominative models may be described as either domain or principle based [6]. Domain-based models describe different areas of focus for sustainable action. Connelly [8] develops the "three pillars" concept and considers the contested nature of sustainability as an inevitability. A framework is developed that maps three competing factors that define the breadth of the field: economic growth, social justice and environmental protection (Fig. 1 [8]), contending that any value or approach prioritises one aspect over any other, and contesting the notion of an ideal solution.

Choucri [5] describes a more comprehensive, domain-based framework, which begins by defining a series of themes; the "core-concepts" of sustainable development (Table 1).

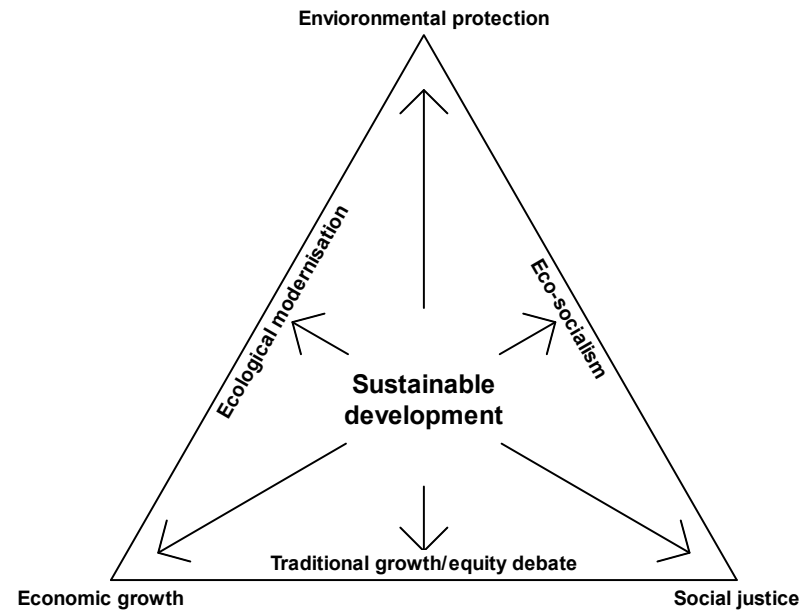

Figure 1: Mapping the three pillars of sustainable development [8].

Table 1: Domains of sustainable development [5].

\begin{tabular}{|l|l|}
\hline \multirow{4}{*}{ Demographic domain } & Population dynamics \\
& Urbanization \\
& Migration and dislocation \\
& Consumption patterns \\
& Unmet basic needs \\
\hline \multirow{2}{*}{ Energy and natural resource domain } & Energy use and source \\
& Forests and land uses \\
& Water uses and sources \\
& Agricultural and rural activities \\
\hline \multirow{2}{*}{ Technology-centred domain } & Trade and finance \\
& Industry and manufacturing \\
& Mobility and transport \\
\hline \multirow{2}{*}{ Domains of decisions and choice } & Conflict and war \\
& Governance and institutions \\
\hline
\end{tabular}


Through mapping these domains as a series of slices of an overall circular domain space, concentric circles then represent the dimensions that constitute each domain: activities, problems, technical solutions, social solutions, international responses (Fig. 2). As domains intersect dimensions, a complex model of sustainable development is created that provides a menu of possible practice to enable sustainable development.

Principle-based nominative models describe a particular concept through generalised ideas. For example, Jabareen [9] introduces a cycle of seven distinct principles, each of which are related, to provide a framework for sustainable development (Fig. 3). Equity, global agenda, eco-form, utopia, integrative management and natural stock capital surround an ethical paradox, which lies at the heart of sustainable development. The tension between sustainability and development allows the coexistence of diverse and often contradictory sustainable practices.

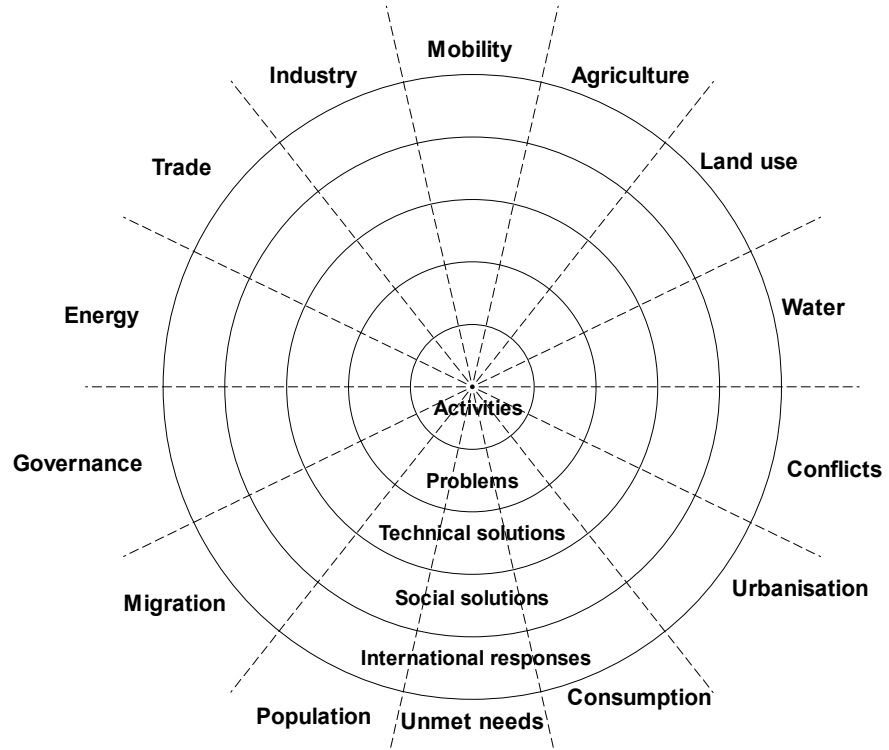

Figure 2: Domains and dimensions of sustainable development [5].

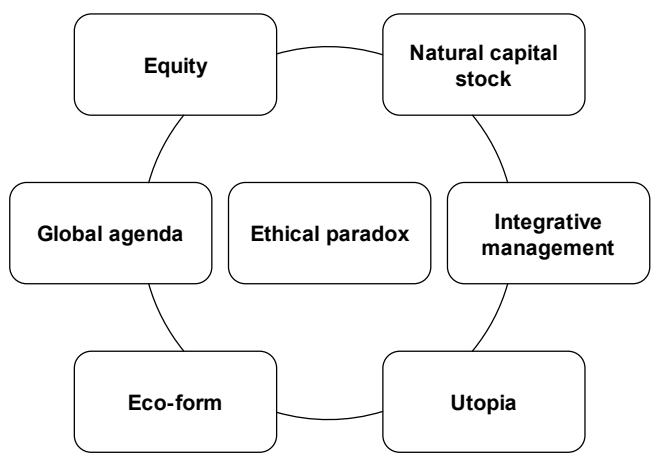

Figure 3: A conceptual framework for sustainable development [9]. 
In another example, Haughton [10] defines five equity principles that might govern the formation of sustainable urban environments. These "equity concerns" are inter-generational, social, geographical, procedural, and inter-species; and each sustainable city type (externally dependent, self-reliant, redesigning cities and fair shares) prioritises these differently.

In the field of design, there are a range of nominative models which are both domainbased models [11], [12] and principle-based [13], [14]. The limitations of the nominative approach are the tendency to advocate a particular set of objective criteria that undermine the possibility for discourse, framing the concept normatively. For example, McDonough and Braungart [12] suggest specific rules for instigating the Next Industrial Revolution.

Similarly, McLennan [13] describes six principles of respect that should be embodied in sustainable design. While valuable, such nominative models capture only a small aspect of the sustainability debate. Through assuming an exhaustive list of generalisable principles, the complexity of the sustainable agenda is reduced to a series of objective criteria that negate contextual application and critical dialogue.

\subsection{Evaluative models of sustainable development}

While nominative models seek to provide a comprehensive overview of a particular topic, evaluative models aim to "apply defined criteria to discuss a concept under certain conditions" [6]. For example, the sustainable development debate might be framed through contrasting political paradigms that imply alternative sustainable agendas. Sylvan and Bennett [15] suggest that sustainable development might take three possible approaches to limit human impact on the environment: reducing human population, changing behaviour to lower impact, and technological innovation to reduce environmental footprints.

O'Riordan [16] captures the second and third of these strategies, through the contrasting view-points of eco-centrism and techno-centrism; the former referring to a human-centred approach to developments, the latter focussing on the power of innovation and markets (Table 2).

At its extreme, the Gaianist tradition places humankind as an integral part of the natural system, emphasising natural ethics and a nurturing relationship with the environment. This aligns with political agendas that value social equity and communalism. By contrast, the extreme techno-centric position assumes an objective relationship to the natural environment, justifying an interventionist approach. This is characterised by a faith in human ingenuity, market forces and technological innovation to overcome the problems of unsustainability.

Table 2: European perspectives on environmental politics and resource management $[16$, p. 85].

\begin{tabular}{|c|c|c|c|}
\hline \multicolumn{2}{|l|}{ Eco-centrism } & \multicolumn{2}{|l|}{ Techno-centrism } \\
\hline Gaianism & Communalism & Accommodation & Intervention \\
\hline $\begin{array}{l}\text { Faith in the } \\
\text { rights of nature } \\
\text { and of the } \\
\text { essential need for } \\
\text { co-evolution of } \\
\text { human and } \\
\text { natural ethics }\end{array}$ & $\begin{array}{l}\text { Faith in co-operative } \\
\text { capabilities of societies } \\
\text { to establish self-reliant } \\
\text { communities based on } \\
\text { renewable resource use } \\
\text { and appropriate } \\
\text { technologies }\end{array}$ & $\begin{array}{l}\text { Faith in the } \\
\text { adaptability of } \\
\text { institutions and } \\
\text { approaches to } \\
\text { assessment and } \\
\text { evaluation to } \\
\text { accommodate to } \\
\text { enviornmental } \\
\text { demands }\end{array}$ & $\begin{array}{l}\text { Faith in the } \\
\text { application of } \\
\text { science, market } \\
\text { forces and } \\
\text { managerial } \\
\text { ingenuity }\end{array}$ \\
\hline
\end{tabular}


Aligning the eco-centric/techno-centric approaches with ethical stances is problematic, as Wilkinson [17] suggests. Eco-centrism, implies a form of environmental stewardship adopting the anthropocentrism explicitly rejected by Gaianist values. Furthermore, Hopwood et al. [7] assert that that socio-economic values do not necessarily align with environmental ones, although they may tend be linked through consistent moral outlooks. Accordingly, in a development of the O'Riordan work, Hopwood et al. [7] restructure this spectrum into a twodimensional visual representation (Fig. 4). Their model uses perpendicular axes to separate environmental and social outlooks, to frame the sustainable development debate through these two competing dimensions. In turn, the authors plot a range of discourses relating to specific institutions, political movements or schools of thought. The directionality of the axis implies sustainable development tends towards simultaneously increasing equality and environmental concerns towards what the authors term, transformational scenarios.

Despite separating the concepts of social equity and environmental concerns, the authors retain the division between the techno-centric and the eco-centric paradigms propagated by O'Riordan. While the former may imply an interventionist approach, framing the argument as a straightforward challenge between technical and ecological approaches, it has the possibility to undermine mutual coexistence. By implication, value is assigned to the transformative paradigms, which require both social equity and respect for the natural environment, irrespective of particular contextual factors. In the exceptional cases of ecofascism, with deep ecology and socialist cornucopias, the concepts sit beyond the sphere of the sustainable development debate.

\subsection{Models of sustainable innovation}

Evaluative models in sustainable design have tended to draw from innovation theory. Commonly, the nature of innovation is classified through the degree of holistic change it addresses [6], [18].

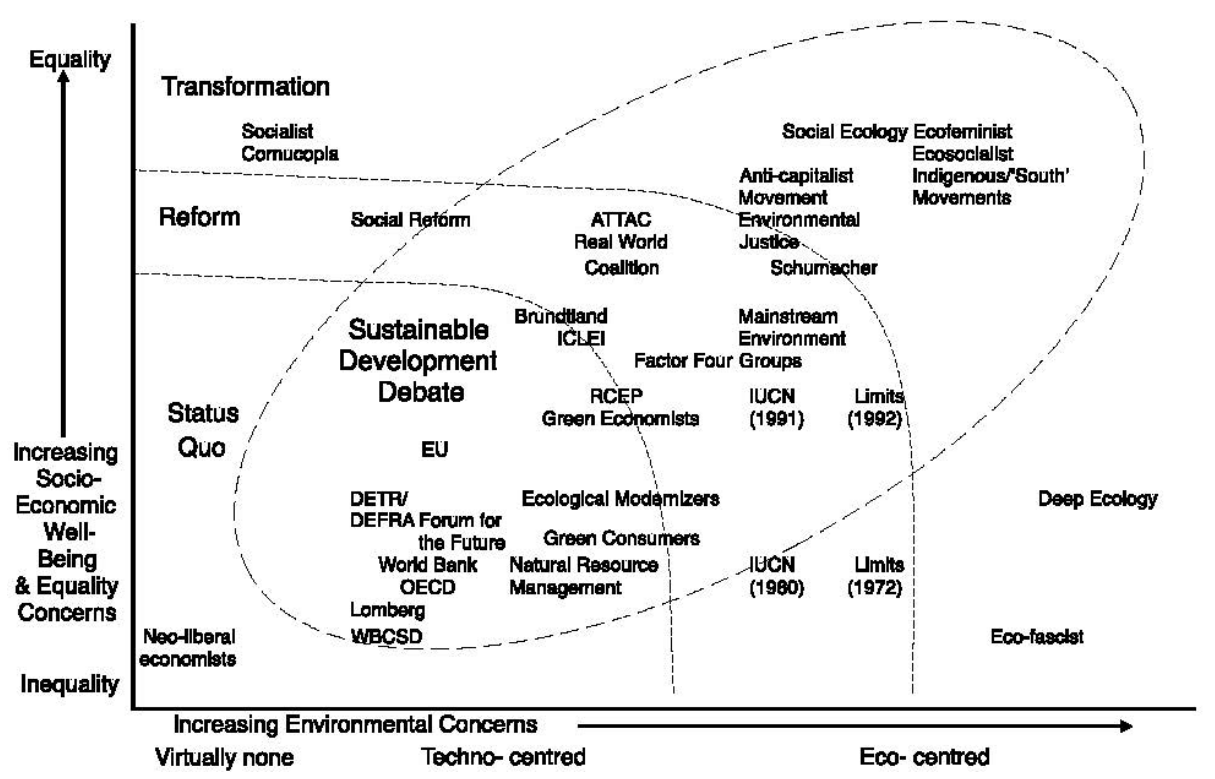

Figure 4: Mapping views on sustainable development [7]. 
For example, Vezzoli and Manzini [19] look at the creation of sustainable products to define four levels of intervention representing increasingly "upstream" approaches from the redesign of existing systems to the re-imagination of entirely new life-styles:

1. The environmental redesign of existing systems,

2. Designing new products and services,

3. Designing new production-consumption systems, and

4. Creating new scenarios for sustainable lifestyles [19, p. xi].

At the first level, the redesign of existing systems deals with a neutralisation of accepted patterns of behaviour; at the second, the processes that generate the need for action are redesigned; at the third, the underlying behaviours that create need for these processes are questioned; while at the fourth, entirely new lifestyles are reimagined. At each level, there is a movement away from solution, focussed on technical intervention towards holistic, humancentred changes.

Dusch et al. [6] draw from the hierarchy of Vezzoli, to create a model of sustainable innovation (Fig. 5). They combine models of sustainable development with those in the field of design, to create a "compound" framework.

This framework is structured through the competing eco-centric and techno-centric domains, echoing the work of O'Riordan [16], to develop a matrix of approaches which compare changes in consumption behaviour with technological innovation. Not only does this allow design activities to be classified and compared in this context, but also provides opportunities to reveal the sustainable potential of a particular activity.

For Dusch et al. [6], the creation of new scenarios represents the highest level of sustainable potential, achievable through major product innovation and behavioural changes.

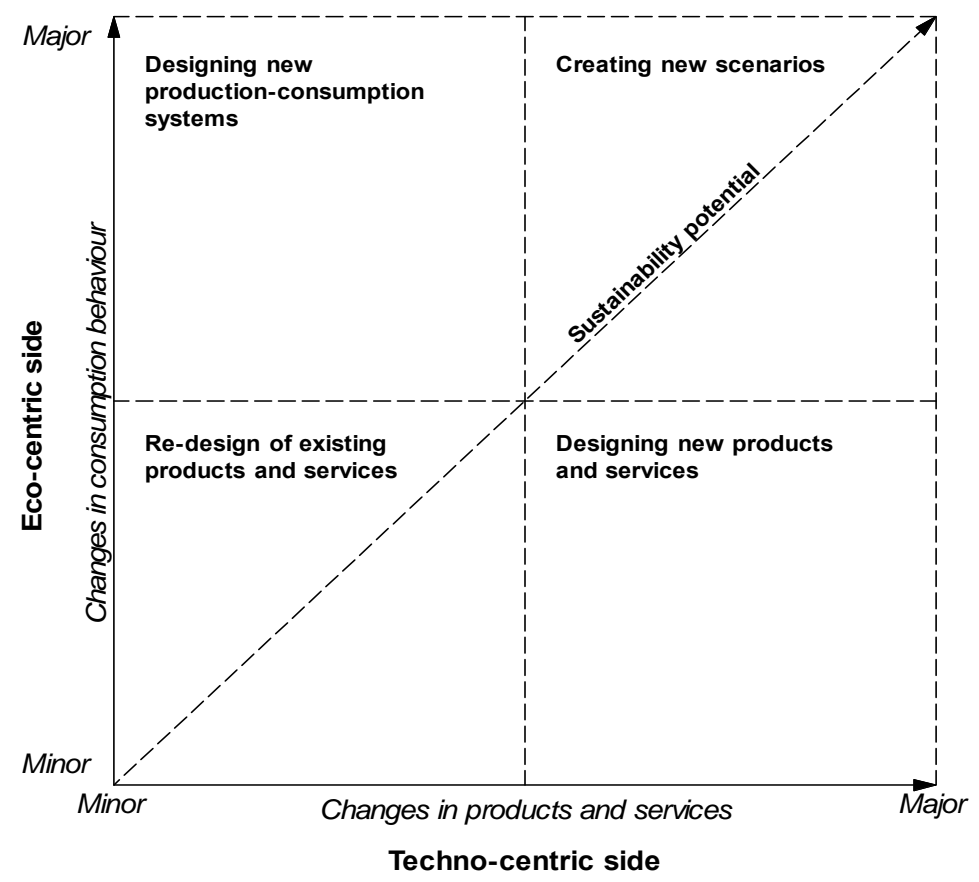

Figure 5: Sustainable design approaches in the context of sustainable development [6]. 
Adams et al. [20] describe three primary dimensions which characterise innovation activities across sustainable organisations: the level to which innovation operated across a firm (whether it was isolated or integrated); the organisation's relationship to society (either insular or systematic); and what the particular focus of the innovation was (technology or people). They suggest that systematic, integrated and people-focussed innovation characterises sustainable business.

Ceschin and Gaziulusoy [21] use the dimensions of innovation focus and relationship to society to frame levels of sustainable product potential in a two-dimensions (Fig. 6): On the $y$ axis, incremental technological innovation is contrasted with a holistic people-centred approach. On the $x$ axis, insular changes that address narrow issues are contrasted with systematic changes that address wider social economic systems. The resultant framework is comparable with Vezzoli's four levels of sustainable design, culminating in the creation of new scenarios at a socio-technical systematic level.

The innovation models considered imply a degree of unilateral consensus that lead towards the common goal of technical and social enhancement. In the cases of Vezzoli and Manzini [19], Dusch et al. [6], and Ceschin and Gaziulusoy [21], there is an implied directionality of design for sustainability, tending toward a combination of innovative product design with more responsible consumer action.

\subsection{Mapping architectural design}

In the field of architecture, Cook and Golton [22] propose a green architectural spectrum, which frames the polarised concepts of transpersonal ecology (a rejection of technology and capitalist politics) with cornucopian environmentalism (a faith in the power of the free market, continuous growth intervention and innovation), echoing the approach outlined by O'Riordan [16].

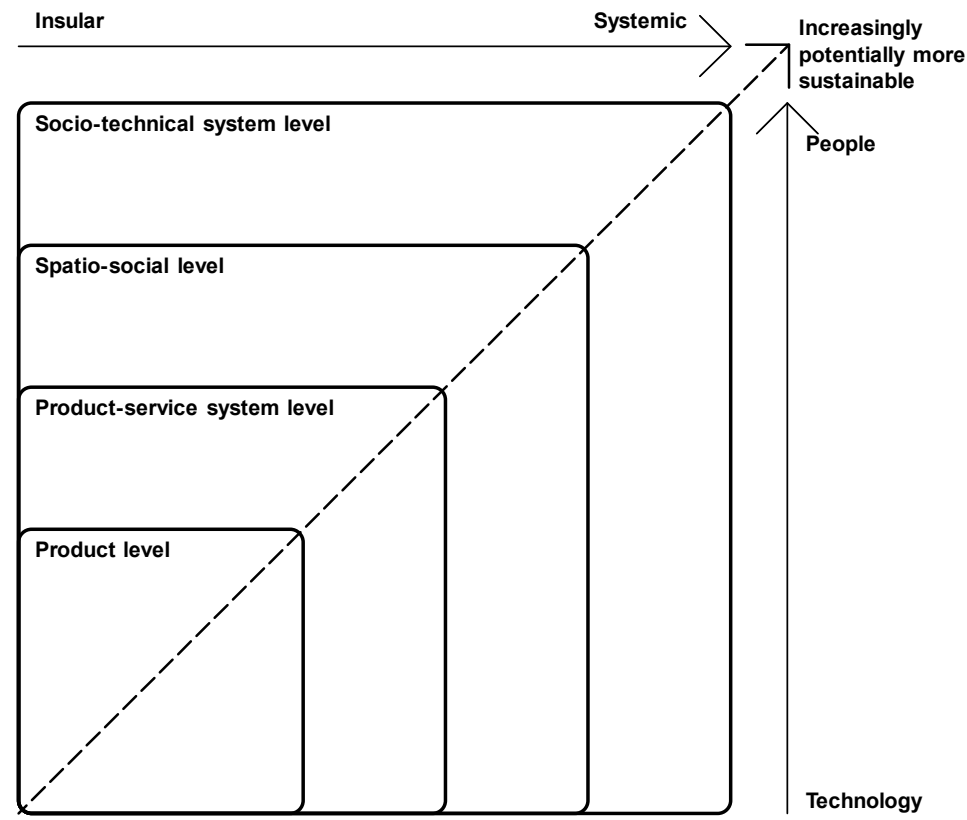

Figure 6: The DFS evolutionary framework [21]. 
Guy and Farmer [23] question the universality of "green" architecture and describe six competing "eco-logics", based on a comprehensive literature review. Each eco-logic represents a range of sustainable design values, often at odds with alternative approaches. For example, while the eco-technic logic may embrace integrated, intelligent technologies, the eco-cultural logic places value on the local, vernacular and low-tech. Likewise, the ecosocial logic is aligned with a participatory social approach; however, their eco-aesthetic logic describes an alienating approach which is seen "as an iconic expression of societal values... to inspire and convey an increasing identification with nature and the nonhuman world" [23, p. 143].

In a discourse analysis of the Passive and Low Energy conference 2014, Alsaadani [24] found that the term "sustainable" architecture was used by the profession to refer to a range of concepts, from performance focussed energy-efficient design, to vernacular and holistic interpretations; however, the author concludes that is this flexibility allows architects to generate numerous contextual responses that utilise multiple sustainable design techniques.

As well as being unrepresentative of the realities of sustainable architecture, the search for a notional consensus undermines the social-constructivist nature of environmental problems. Indeed, as Hannigan [25] suggests: "nature, ecology and environmentalism - are by no means fixed in meaning but instead are both socially constructed and contested" [25, p. 126]. It is through embracing this diversity of approaches that conflicting paradigms may act together to achieve particular limited goals, as well as challenge the hegemony of scientific certainty [3]. As Jamison [26] asserts, interpretations of environmentalism are based on contextual factors and discursive frameworks which are bound to wider societal values [26, p. 74].

\section{DEVELOPING AN ARCHITECTURAL FRAMEWORK}

Based on the inadequate application to architecture of existing sustainable models, an alternative framework is presented. The eco-centric and techno-centric dimensions are maintained, representing behavioural (building users) and technological (building fabric) characteristics, respectively [15], [16]. Drawing from Dusch et al. [6], the perpendicular axes represent these contrasting dimensions, in which high-tech strategic approaches are contrasted with low-tech ones on the techno-centric axis; while authoritative versus participatory approaches define the limits of the eco-centric axis (Fig. 7). As Guy and Farmer [23] have suggested, the trend towards product innovation and participatory action [6], [21] does not necessarily represent current sustainable architectural design. In their analysis, some practices adopt intentionally low-tech approaches drawn from vernacular traditions, while others utilise technical enhancements to reduce the need for user engagement.

The axes define four quadrants for potential action that combine high-tech and low-tech approaches with participatory and authoritative ones. Each quadrant is based on its defined relationship between eco-centrism and techno-centrism. The framework allows for centrist approaches, which combine contrasting attitudes toward technology with mixed social approaches. The resulting framework (Fig. 8) is a matrix of contrasting eco- and technocentric paradigms, and describes eight potential extreme positions at its edges. The range of sustainable architectural practice may be used to populate this spectrum.

The resulting framework provides a map of actual and potential sustainable design strategies in architecture. It allows the range of practice to be mapped and organised to reveal the complexity of sustainable design. This has the potential to guide future sustainable design strategy [5], through realising potential alternative opportunities. It may also be seen as an aspirational tool, where practitioners can identify their location on the axis and work towards a particular approach. 


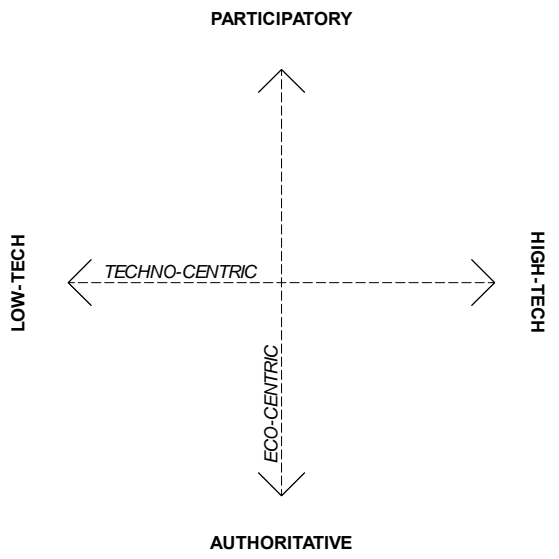

Figure 7: The axes of a framework for sustainable architectural design.

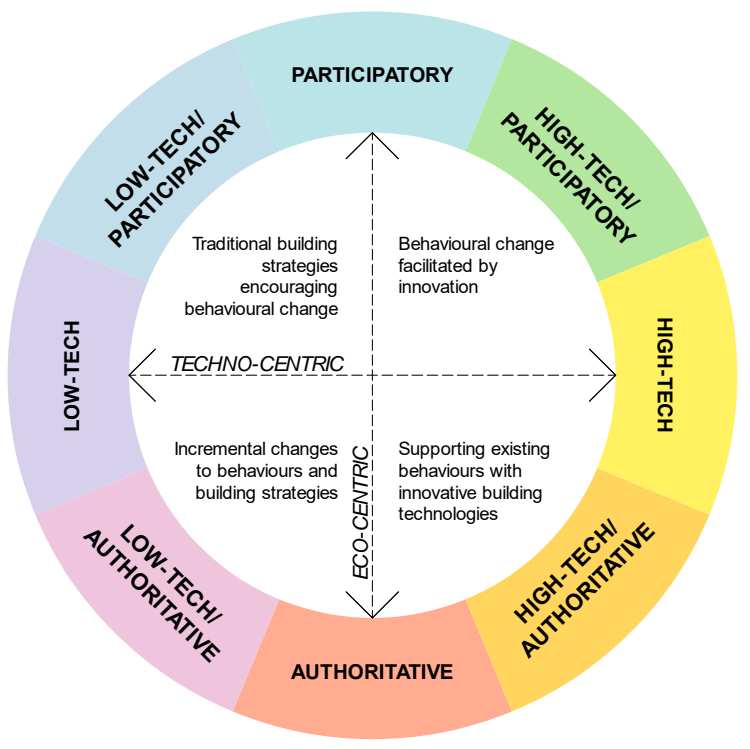

Figure 8: A framework for sustainable architectural design.

The framework defines four quadrants that are aligned with different sustainable paradigms represented in the literature. On the bottom left, the low-tech/authoritative quadrant is defined by incremental changes to behaviour and building strategies. This is loosely aligned with the notion of accommodation defined by O'Riordan [16], which places faith in institutions to adapt to environmental challenges and continue with minor changes to existing managerial and political structures. O'Riordan describes this as "tinkering at the margins" in order to maintain the status quo [16]. Typically, this might involve the piecemeal adoption of technologies in isolation, undertaken on a small scale, with limited changes to behaviours or attitudes. 
The low-tech/participatory sector in the top left is characterised by an approach that adopts simple technologies, often drawing from the vernacular and traditional construction, in combination with user behavioural changes that reduce the environmental impact of lifestyles. This quadrant aligns with the eco-centric and eco-cultural paradigms described by Guy and Farmer [23]. Typically, it is highly contextual and utilises local materials and crafts or seeks environmental stability. Participatory action is important, and it values stakeholders as integral parts of the cultural and environmental context.

In the bottom right corner, the high-tech/authoritative quadrant is aligned with the interventionist and techno-centric paradigms [16]. This approach values innovation through technological progress, focussing on building performance over changes in consumption behaviour. Efficiency and optimisation are prioritised as a means to address environmental problems [23]. Placing the role of technology central to the sustainable cause has been aligned with neoliberal political views which place faith in the free market, the power of human ingenuity and unlimited potential for growth [27].

Finally, the upper right quadrant describes an approach that combines participatory action with technological enhancement. For Dusch et al. [6], this represents the optimal approach to sustainable design, which seeks to transform both behaviours and products. Hopwood et al. [7] describe this radical approach as being used by reformists who argue for a fundamental shift in the structure of society, aligning with the environmental justice movement. Often it represents a decentralisation of power, with a focus on marginal or under-represented communities. In architecture, such an approach might be typified by radical communities that adopt innovative technologies to facilitate low-impact communal living.

Although building on the literature, the proposed framework is unique in its specificity to architecture. Previous design frameworks imply sustainable development and optimal responses combine technical innovation with changes in consumption behaviour (e.g. Dusch et al. [6]) or propose hierarchical intervention structures (e.g. Vezzoli and Manzini [19]). These approaches fail to capture the heterogeneity of architectural design, in which high-tech and low-tech solutions, as well as participatory and authoritative strategies, coexist; where they are equally valid and are contextually determined [23]. The proposed framework captures the range of sustainable approaches and organises the concepts into a coherent visualisation.

\section{CONCLUSION}

The sustainable architecture framework presented seeks to capture the range of architectural practice and provide an evaluative tool for future design action. If the role of sustainable development is to reduce human impact through changes in behaviour or reducing the impact of those behaviours, differing sustainable design approaches can be captured through the contrasting domains of eco-centrism and techno-centrism. This provides an analytical structure that allows comparison of alternative design paradigms. Existing design frameworks, drawn from innovation theory, could be considered inadequate for architectural design, as assuming a mono-directional focus on sustainable development denies the existence of competing contextualised paradigms.

The value of the proposed framework lies in its capacity to structure the complex realm of sustainable architectural design and allow the spectrum of sustainable approaches to be simultaneously visualised, while exposing opportunities for enhanced future practice. As an analytical tool, it may be used as an educational device, to encourage critical and reflective engagement with sustainable design. It allows the hegemony of technological and scientific knowledge to be challenged, providing genuine alternatives for sustainable design action. 
This paper forms the basis of an ongoing analysis of contemporary design practice in the UK. To validate the framework and assess its relevance to sustainable practice, 26 architects have been interviewed using in-depth, semi-structured techniques [28]. This allowed the researchers to explore emergent themes and uncover motivational factors for sustainable design. A sample was made from three populations: The members of the Royal Institute of British Architects (RIBA) Sustainable Futures Group, practitioners who had won national or regional awards for sustainable design, and practitioners who self-identified as sustainable designers. A "snowball" technique was used to expand the sample within each group.

Interviews were loosely structured using the framework described in this paper and questions focussed on the role of technological innovation and participatory strategies in practice. Guided by the responses of the interviewees, this often took the form of the description of an exemplary building. Each interview was audio recorded and professionally transcribed. Data were analysed through a process of coding, domain analysis, revealing relationships, making inferences, summarising, seeking negative cases and theory generation. This was based on the method set out by Glaser and Strauss [29]. The framework developed in this paper provided analytical categories that defined the subsequent domains used for coding categorisation.

\section{REFERENCES}

[1] Rittel, H.W.J. \& Webber, M.M., Dilemmas in a general theory of planning. Policy Sciences, 4, pp. 155-169, 1973.

[2] Brundtland, G. et al., Our Common Future ('Brundtland Report'), Oxford University Press: USA, 1987.

[3] Guy, S. \& Moore, S.A., Sustainable architecture and the pluralist imagination. Journal of Architectural Education, 60(4), pp. 15-23, 2007.

[4] Brennan, J., Green architecture: Style over content. Architectural Design, 67(1-2), pp. 23-25, 1997.

[5] Choucri, N., Mapping Sustainability Knowledge E-networking and the Value Chain, ed. D. Mistree, F. Haghseta, T. Mezher, W.R. Baker \& C.I. Ortiz, SpringerLink, Springer: Dordrecht, 2007.

[6] Dusch, B., Crilly, N. \& Moultrie, J., Developing a framework for mapping sustainable design activities. DRS International Conference: Design and Complexity, pp. 383398, 2010.

[7] Hopwood, B., Mellor, M. \& O'Brien, G., Sustainable development: Mapping different approaches. Sustainable Development, 13(1), pp. 38-52, 2005.

[8] Connelly, S., Mapping sustainable development as a contested concept. Local Environment, 12(3), pp. 259-278, 2007.

[9] Jabareen, Y., A New Conceptual Framework for Sustainable Development, Springer Science and Business Media: Dordrecht, pp. 179-192, 2008.

[10] Haughton, G., Environmental justice and the sustainable city. Journal of Planning Education and Research, 18(3), pp. 233-243, 1999.

[11] Fuad-Luke, A., Design Activism: Beautiful Strangeness for a Sustainable World, Earthscan: Oxford, 2009.

[12] McDonough, W. \& Braungart, M., The next industrial revolution. The Atlantic Monthly, 282(4), pp. 82-92, 1998.

[13] McLennan, J.F., The Philosophy of Sustainable Design, Ecotone: Kansas City, MO, 2004.

[14] Sev, A., How can the construction industry contribute to sustainable development? A conceptual framework. Sustainable Development, 17(3), pp. 161-173, 2009. 
[15] Sylvan, R. \& Bennett, D., The Greening of Ethics: From Human Chauvinism to Deepgreen Theory, White Horse, 1994.

[16] O'Riordan, T., The challenge for environmentalism.p New Models in Geography, pp. 77, 1989.

[17] Wilkinson, S., Conceptual understanding of sustainability in the Australian property sector. Property Management, 31(3), pp. 260-272, 2013.

[18] Tischner, U. \& Verkuijl, M., Design for (social) sustainability and radical change. Perspectives on Radical Changes to Sustain-able Consumption and Production (SCP), 20, p. 199, 2006.

[19] Vezzoli, C.A. \& Manzini, E., Design for Environmental Sustainability, Springer Science and Business Media, 2008.

[20] Adams, R., Jeanrenaud, S., Bessant, J., Denyer, D. \& Overy, P., Sustainability-oriented innovation: A systematic review. International Journal of Management Reviews, 18(2), pp. 180-205, 2016.

[21] Ceschin, F. \& Gaziulusoy, I., Evolution of design for sustainability: From product design to design for system innovations and transitions. Design Studies, 47, pp. 118163, 2016.

[22] Cook, S.J. \& Golton, B., Sustainable development concepts and practice in the built environment. A UK perspective. CIB TG, 16, pp. 6-9, 1994.

[23] Guy, S. \& Farmer, G., Reinterpreting sustainable architecture: The place of technology. Journal of Architectural Education, 54(3), pp. 140-148, 2001.

[24] Alsaadani, S., Deciphering the code of 'sustainable' architecture: Exploring the discourse of PLEA 2014, 2014.

[25] Hannigan, J., Environmental Sociology, Routledge, 2014.

[26] Jamison, A., The Making of Green Knowledge: Environmental Politics and Cultural Transformation, Cambridge University Press, 2001.

[27] Davidson, K., A typology to categorize the ideologies of actors in the sustainable development debate. Sustainable Development, 22(1), pp. 1-14, 2014.

[28] Patton, M.Q. Qualitative Evaluation Methods, Sage: Beverly Hills, 1980.

[29] Glaser, B.G. \& Strauss, A.L., The Discovery of Grounded Theory: Strategies for Qualitative Research, Transaction Publishers: New Jersey, 2009. 